\title{
Utjecaj kvasaca na kvalitetu žitnog destilata
}

\begin{abstract}
Sažetak
Izbor kvasca za proizvodnju žitnog destilata može značajno utjecati na randman i koncentraciju etanola te konačnu kvalitetu proizvoda. Cilj rada bio je ispitati utjecaj dvije različite vrste kvasaca iz roda Saccharomyces na kvalitetu destilata dobivenog dvostrukom destilacijom fermentirane ječmene sladovine na jednostavnom destilacijskom uređaju. Korištena su dva kvasca, Saccharomyces cerevisiae komercijalnog naziva FERMOALE AY4, te kvasac Saccharomyces cerevisiae (ex. bayanus) komercijalnog naziva EC1118. Kemijskom analizom utvrđeno je kako je primjenom kvasca AY4 postignuta bolja iskoristivost šećera iz ječmene sladovine (3 \% više etanola) i niža titracijska kiselost destilata. Plinskom kromatografijom utvrđene su koncentracije acetaldehida u oba uzorka iznad uobičajenih, pa je u uzorku destilata dobivenog korištenjem kvasca AY4 determinirano 274 mg L-1 a.a., a u uzorku dobivenom sa kvascem EC1118, 356 mg L-1 a.a. Nadalje, koncentracije viših alkohola u oba su uzorka bile iznad uobičajenih. U uzorku destilata AY4 determinirano je 2179 mg L-1 a.a, dok uzorak destilata EC1118 zbog determiniranih $3602 \mathrm{mg} \mathrm{L-1} \mathrm{a.a.} \mathrm{ukupnih} \mathrm{viših} \mathrm{alkohola} \mathrm{ulazi} \mathrm{u} \mathrm{kategoriju} \mathrm{destilata} \mathrm{niže} \mathrm{kvalitete.} \mathrm{Uzorak}$ destilata EC1118 bio je bogatiji etil acetatom, dok je uzorak destilata AY4 imao više koncentracije ostalih estera što je rezultiralo kompleksnijom aromom i punijim okusom destilata AY4.

Ključne riječi: žitni destilat, kvasac, hlapivi spojevi, esteri, viši alkoholi
\end{abstract}

\section{Uvod}

Kvasci i proces alkoholne fermentacije imaju vrlo značajnu ulogu u formiranju kvalitete jakih alkoholnih pića. Izvor hlapivih spojeva u žitnim destilatima koji čine bazu za whisky jesu sirovina, odnosno žitarica koja se koristi, produkti metabolizma kvasca, te kontaminacija drugim mikroorganizmima prisutna u alkoholnoj fermentaciji sladovine (Hough i sur., 1982; Young, 1996; Boulton i Quain, 2001; Slaughter, 2003). Na važnost kvasca u formiranju arome alkoholnih pića upućuje istraživanje Nykänena (1985) gdje je dokazano da kvasac u istim uvjetima alkoholne fermentacije, ali u različitim sirovinama daju nevjerojatno sličan aromatski i okusni sastav pića. Temperatura fermentacije ima veoma važnu ulogu. Komercijalni kvasac za proizvodnju žitnih destilata dobro fermentira na temperaturama $34-35^{\circ} \mathrm{C}$, a na višim temperaturama aktivnost mu značajno opada (Campbell, 2003). U pravilu, viša temperatura fermentacije znači i brži rast kvasca u proporciji sa dostupnim $\alpha$-amino dušikom, što rezultira i većom proizvodnjom viših alkohola. S druge strane, kako veći rast kvasaca uzrokuje sporiji nastanak CoA, proizvodnja estera je reducirana. (Enari i sur., 1970). Sladovina dobivena ukomljenim ili neukomljenim žitaricama predstavlja medij bogat ugljikom, dušikom i mineralnim hranjivima za kvasac, dok primarni nedostatak jesu nezasićene masne kiseline i steroli (Campbell, 2003). Proces ukomljavanja predstavlja važan dio u procesu proizvodnje whisky-a koji uključuje miješanje mljevenog žitnog slada s toplom vodom do ciljane temperatura od $64,5^{\circ} \mathrm{C}$. Postignuta temperatura zadržava se kroz 30-60 min. što pogoduje djelovanju amilolitičkih i proteolitič-

doc. dr. sc. Marin Mihaljević žulj, MarkoViskić, mag.ing., doc. dr. sc. Luna Maslov Bandić,

Sveučilište u Zagrebu Agronomski fakultet, Svetošimunska cesta 25, 10000 Zagreb, Hrvatska

Ivan Počepan, univ. bacc.,. Student Ms diplomski studij, Sveučilište u Zagrebu, Agronomski fakultet, Svetošimunska cesta 25, 10000 Zagreb, Hrvatska

Autorza korespondenciju:mmihaljevic@agr.hr 
kih enzima prisutnih u žitaricama čime se iz škroba oslobađaju fermentabilni šećeri, kao što su glukoza, maltoza i maltotrioza (Dolan, 2003). Međutim, na temperaturama od $63-65{ }^{\circ} \mathrm{C}$ dolazi do smanjenja broja mikroorganizama, ali ne dolazi do sterilizacije sladovine (Geddes, 1985). Najčešći i potencijalno najproblematičniji mikroorganizmi u destilerijama su bakterije mliječnog vrenja (Dolan, 1976). Mikrobiološka stabilnost održava se smanjenjem pH vrijednosti tijekom fermentacije, anaerobnim uvjetima, otopljenim CO2 i manjkom šećera krajem fermentacije (Hammond i sur., 1999).

Od karbonilnih spojeva u destilatima dominira acetaldehid, direktan nusproizvod alkoholne fermentacije. U nižim koncentracijama daje miris lješnjaka, višanja ili prezrele jabuke, no više koncentracije su nepovoljne zbog snažnog oporog mirisa. Osim što u visokim koncentracijama ima senzorno negativan utjecaj, kemijski je vrlo reaktivan te može izazvati štetne simptome kod ljudi. Njegov sadržaj u destilatu primarno je vezan uz korišteni kvasac za fermentaciju, tijek fermentacije i odvajanje tokova tijekom destilacije (Kwak i sur., 2015).

Postoje zamjetne razlike u proizvodnji aldehida između kvasaca, što je objašnjeno različitom aktivnošću piruvat dekarboksilaze kod pojedinih sojeva kvasca. Ostali čimbenici koji mogu prouzročiti više razine acetaldehida jesu nedostatak hranjivih tvari tijekom fermentacije, oksidacija alkohola, oksidativna Strecker degradacija aminokiselina te autooksidacija masnih kiselina (Nykänen, 1985).

Viši alkoholi su kvantitativno najveća grupa hlapivih spojeva u alkoholnim pićima. Ova skupina se sastoji od alifatskih i aromatskih alkohola čiji nastanak može derivirati od amino kiselina. Unutar skupine alifatskih alkohola najzastupljeniji su 1-propanol, 2-metil-1-propanol (izobutil), 2-metil-1-butanol (aktivni amilni alkohol), 3-metil-1-butanol (izoamilni alkohol) te aromatski alkohol 2-feniletanol. Metilbutanoli su najmnogobrojniji nusproizvod kvasca u destilatu te se u usporedbi s ostalim višim alkoholima javljaju u mnogo višim koncentracijama (Spaho, 2017; Christoph i Bauer-Christoph, 2007).

Octena kiselina zastupa više od $90 \%$ (v/v) ukupne kiselosti destilata. Javlja se kao nusprodukt alkoholne fermentacije, u prisustvu kisika ju proizvodi kvasac katabolizmom šećera, ili se stvara oksidacijom acetaldehida. Dakle sadržaj octene kiseline u piću ovisi o korištenom soju kvasca (Spaho, 2017). Povišene koncentracije octene kiseline u fermentiranoj sladovini, kao i smanjena razina etanola, upućuju na kontaminaciju octenim bakterijama. Zbog oporog mirisa i kiselog okusa poželjne su minimalne koncentracije ovog spoja u destilatu. Ostale hlapive kiseline prisutne su u mnogo nižim koncentracijama. To su karboksilne kiseline i masne kiseline kao mravlja, propionska, maslačna, izomaslačna, kapronska, undekanska, miristinska, valerijanska, 3-metilbutanska, 2-metilbutanska i pelargonska kiselina (Spaho, 2017; Silva i sur., 2000.).

Esteri predstavljaju zasebnu skupinu hlapivih spojeva nastalih tijekom fermentacije metabolizmom kvasaca. Esteri se obično povezuju s ugodnim voćnim i cvjetnim aromama.

Najdominantniji ester $\mathrm{u}$ alkoholnim pićima je etil acetat koji iznad koncentracije od $180 \mathrm{~g}$ hL-1 a.a. može dati kiseli karakter mirisa (Spaho, 2017). Ostali esteri kao što su etil heksanoat, etl oktanoat i etil dekanoat su poželjeni u destilatima zbog svog doprinosa voćnim i cvjetnim aromama. Dietil sukcinat je ester koji potječe uglavnom od bakteriološke aktivnosti tijekom alkoholne fermentacije te $u$ procesu destilacije destilira u zadnjem toku. $U$ destilatu asocira na miris kamfora. Slično ovome ponaša se i etil laktat koji u nižim koncentracijama od 154 mg L-1 a.a. može pridonositi punoći destilata (Soufleros i sur., 2004; Christoph i Bauer-Christoph, 2007; Spaho, 2017). 


\section{Materijali i metode}

Proces ošećeravanja ječmene kaše proveden je u svibnju 2019. godine u mikropivovari Angeluš u Svetom Ivanu Zelini, Hrvatska. Na mlinu za slad samljeveno je 7 kg Pilsner Malta (IREX aroma, Hrvatska) te dodano u $30 \mathrm{~L}$ vode u tanku za ukomljavanje. Vrijednost pH korigirana je na 5.2 dodatkom $2 \mathrm{~mL}$ mliječne kiseline nakon čega je uključen grijač tanka i lopatica za miješanje komine. Kada je komina dostigla ciljanu temperaturu od $62{ }^{\circ} \mathrm{C}$, grijač je isključen te je započeo proces ošećeravanja u trajanju od 60 minuta uz održavanje navedene temperature. Sladovina je filtrirana i ohlađena na $20{ }^{\circ} \mathrm{C}$ te je refraktrometrom izmjerena specifična težina od 1.057 ( $57^{\circ} \mathrm{Oe}$ ). Dobivena sladovina je zatim raspodijeljena u dva bocuna od $10 \mathrm{~L}$. Pri inokulaciji korišten je dehidrirani kvasac Fermoale AY4 (Saccharomyces cerevisiae) i Lalvin EC 1118 (Saccharomyces cerevisiae ex. bayanus). Svaki kvasac je rehidriran u toploj vodi na 30 ${ }^{\circ} \mathrm{C}$. Sladovina je fermentirala na temperaturi od $20-22{ }^{\circ} \mathrm{C}$ sedam dana nakon čega je uslijedila destilacija.

Fermentirana sladovina destilirana je na jednostavnom uređaju tipa „alambic“ kapaciteta 5 L. Prvom destilacijom sladovine fermentirane kvascem AY4 (bocun A) bez odvajanja tokova dobiveno je $1540 \mathrm{~mL}$ destilata (destilat A) alkoholne jakosti 26,6 \% vol. Istim postupkom je iz sladovine fermentirane kvascem EC1118 (bocuna B) dobiveno $1640 \mathrm{~mL}$ destilata (destilat B) alkoholne jakosti $24,3 \%$ vol. Zatim je provedena druga destilacija sa oba destilata; od svakoga je u prvim tokom odvojen $1 \%$ volumena $(A-15 \mathrm{~mL}, B-16 \mathrm{~mL}$ ) te je dobiveno $400 \mathrm{~mL}$ srednjeg toka (iznad $50 \%$ volumne jakosti alkohola), treći tok nije odvajan već je destilacija završena. Ovim postupkom je dobiveno $400 \mathrm{~mL}$ destilata A alkoholne jakosti $67 \%$ vol., odnosno $400 \mathrm{~mL}$ destilata B alkoholne jakosti $64 \%$ vol.

$\mathrm{Na}$ ovim uzorcima je zatim provedena analiza kemijskog sastava destilata (alkoholna jakost, titracijska kiselost i ukupni esteri) prema metodama propisanim Pravilnikom o analitičkim metodama za jaka alkoholna pića (NN 138/2005).

Koncentracije metanola, n-propanola, izobutanola, amilnih alkohola (smjesa izomera 3metil-1-butanola i 2-metil-1-butanola), feniletanola, etil heksanoata, etil oktanoata, etil dekanoata, etil laktata, dietil sukcinata i acetaldehida određene su metodom plinske kromatografije sa SRI $8610 \mathrm{C}$ plinskim kromatografom, FID detektorom na koloni MXT WAX 30m, 0.53 $\mathrm{mm}, 0.25 \mathrm{um}$ df u sljedećim uvjetima; $\mathrm{Tpoč}=40^{\circ} \mathrm{C} \rightarrow$ hold $5 \mathrm{~min} \rightarrow \mathrm{Tkon}=220^{\circ} \mathrm{C}, \mathrm{DT}=5^{\circ} \mathrm{C} / \mathrm{min}$, $\mathrm{T}$ (injektor) $=230^{\circ} \mathrm{C}, \mathrm{T}$ (detektor) $=250^{\circ} \mathrm{C}$.

Statistička analiza podataka provedena je s analizom varijance (ANOVA). Za testiranje srednjih vrijednosti korišten je Tukey HSD test pri $p<0.05$. Analiza je provedena u programu SAS Studio, $\mathrm{SAS}^{\circledR}$ OnDemand for Academics.

\section{Rezultati i rasprava}

Prve razlike između dvaju korištenih kvasca javile su se već u fermentaciji. Kvasac A (Fermoale AY4) brže je i burnije fermentirao sa stvaranjem velike količine pjene u usporedbi sa kvascem B (Lalvin EC1118) koji je fermentirao sporije bez pjenjenja. Ovo je očekivao jer je kvasac AY4 pivski kvasac selekcioniran prema svojoj dobroj adaptabilnosti na uvjete u sladovini, odnosno visoke koncentracije disaharida maltoze i iskorištavanje tog šećera (https://www. aeb-group.com/en/food-beverage/fermoale-ay4). EC1118 vinski je kvasac, te dodatno tome i fruktofilan (https://www.lallemandbrewing.com/en/continental-europe/product-details/lalvin-ec-1118/). Stoga je vjerojatno uzrok sporije fermentacije kvasca EC1118 lošija adaptabilnost na uvjete u sladovini. U Tablici 1 prikazani su rezultati kemijske analize sastava destilata. Alkoholna jakost očekivano je veća u uzorku A. Titracijska kiselost je tri puta manja u uzorku A, što je opravdano činjenicom kako je to pivski kvasac selekcioniran kako bi stvarao čim manje octene kiseline. Prema kemijskoj analizi u uzorku B utvrđene su više koncentracije ukupnih 
estera, što je očekivano s obzirom na njegovu namjenu. Titracijska metoda analize ukupnih estera prikazuje koncentraciju ukupnih estera preračunato na etil acetat, dok je sadržaj ostalih, pojedinačnih estera prikazan u grafikonu 1.

Tablica 1. Analiza kemijskog sastava destilata A i B

Table1. Chemical analysis of $A$ and $B$ distillate

\begin{tabular}{ccccc}
\hline & $\begin{array}{c}\text { Volumen/ } \\
\text { Volume }(\mathrm{mL})\end{array}$ & $\begin{array}{c}\text { Alkoholna jakost/ } \\
\text { Alcohol strenght } \\
(\% \text { vol. })\end{array}$ & $\begin{array}{c}\text { Titracijska kiselost/ } \\
\text { titrable acidity } \\
(\text { mg L-1 a.a. })^{1)}\end{array}$ & $\begin{array}{c}\text { Ukupni esteri/ } \\
\text { Total esters }\end{array}$ \\
\hline (mg L-1 a.a.) $)^{2)}$ & & & & 53,73 \\
\hline A (AY4) & 400 & 67 & 150,00 & 753,52 \\
\hline B (EC1118) & 400 & 64 & 797,50 \\
\hline
\end{tabular}

1) izraženo kao octena kiselina/expressed as acetic acid,

${ }^{2)}$ izraženo kao etil acetat/expressed as ethyl acetate

Acetaldehid čini oko 90 \% svih prisutnih aldehida u alkoholnom piću, te se prema Nykänenu i Suomalainenu (1983) koncentracije aldehida kreću od 40 do 220 mg L-1 a.a. u različitim tipovima whisky-a, a zabilježeni su slučajevi brandy-a slabije kvalitete sa čak 600 mg L-1 a.a. acetaldehida. U nižim koncentracijama daje miris lješnjaka, višanja ili prezrele jabuke, ali više koncentracije su nepovoljne zbog snažnog oporog mirisa. Koncentracije acetaldehida (Tablica 2) su povišene u oba uzorka whisky-a, ali pivski kvasac A ipak je dao niže koncentracije. Njegovo nastajanje primarno je vezano uz korišteni kvasac za fermentaciju i tijek fermentacije (Kwak i sur., 2015). Ovo je objašnjeno različitom aktivnošću piruvat dekarboksilaze kod pojedinih sojeva kvasca. Daljnji čimbenici koji mogu prouzročiti više razine acetaldehida jesu nedostatak hranjivih tvari tijekom fermentacije, oksidacija alkohola, oksidativna Strecker degradacija aminokiselina te autooksidacija masnih kiselina (Kwak i sur., 2015).

Metanol ne nastaje tijekom fermentacije kao viši alkoholi, već enzimatskim oslobađanjem metoksilnih grupa iz pektina (Spaho, 2017). Vrijednosti metanola u whisky-u rijetko premašuju 500 mg L-1 (Nykänen, 1985), pa su tako i u uzorcima A i B te vrijednosti niske.

Tablica 2. Koncentracije hlapivih spojeva u žitnim destilatima

Table 2. Concentrations of volatile compounds in grain distillates.

\begin{tabular}{ccc}
\hline Spoj/Compound (mg L-1 a.a.) & A (AY4) & B (EC1118) \\
\hline Acetaldehid/Acetaldehyde & $273,93 \mathrm{~b}$ & $356,16 \mathrm{a}$ \\
\hline Metanol/Methanol & $96,04 \mathrm{~b}$ & $200,76 \mathrm{a}$ \\
\hline n-Propanol/n-Propanol & $452,15 \mathrm{~b}$ & $596,44 \mathrm{a}$ \\
\hline Izobutanol/Isobutanol & $293,19 \mathrm{~b}$ & $387,41 \mathrm{a}$ \\
\hline n-Butanol/n-Butanol & $5,27 \mathrm{~b}$ & $13,26 \mathrm{a}$ \\
\hline Feniletanol/Phenylethanol & $18,03 \mathrm{~b}$ & $31,39 \mathrm{a}$ \\
\hline Izamilni alkoholi/Isoamyl alcohols & $1410,88 \mathrm{~b}$ & $2573,42 \mathrm{a}$ \\
\hline Ukupni viši alkoholi/ & 2179,52 & 3601,92 \\
\hline Total higher alcohols & & \\
\hline
\end{tabular}

n.d. - nije detektirano/not detected. Prikazane srednje vrijednosti sa različitim slovima u istom retku značajno se međusobno razlikuju prema Tukey-evom testu $(p<0.05) /$ Means with different letters in the same row are different according to the Tukey test $(p<0.05)$. 
Viši alkoholi imaju bitnu ulogu u aromatskom profilu destilata. U nižim koncentracijama daju ugodan okus i karakter destilatu, dok više koncentracije mogu biti negativne tako što daju težak i opor miris i okus (Soufleros i sur., 2004; Cortes i Fernandez, 2005). Povišene koncentracije viših alkohola, više od 3500 mg L-1 a.a., smatraju se indikatorom niže kvalitete (Cortes i sur., 2011). Kvasac uzorka B sintetizirao je daleko više viših alkohola od kvasca uzorka A. Ova pojava može upućivati na veću potrebu kvasca B za aminokiselinama tijekom fermentacije. Prema Spaho (2017) koncentracija viših alkohola ovise o sirovini, uvjetima fermentacije, tehnici destilacije i destilacijskoj opremi.

Esteri masnih kiselina brojčano su najveća skupina spojeva u alkoholnim pićima. Kao hlapivi spojevi koji daju ugodan miris, imaju bitnu ulogu u aromi pića. Uloga i doprinos pojedinih estera u velikoj mjeri ovisi o njihovoj koncentraciji. Istraživanja potvrđuju činjenicu kako se različiti sojevi kvasaca razlikuju u proizvodnji estera (Sponholz i sur., 1974., Nykänen i sur., 1977a i 1977b).

Kemijskom analizom utvrđena je koncentracija ukupnih estera izraženih kao etil acetat, a kromatografijom koncentracije pojedinačnih estera, etil heksanoata, etil laktata, etil oktanoata, etil dekanoata te dietil sukcinata (Grafikon 1). Etil acetat je ester koji se u destilatima javlja u najvećoj mjeri te u umjerenim koncentracijama pridonosi ugodnom mirisu i voćnom karakteru, dok u visokim koncentracijama daje karakterističan i oštar miris na ljepilo. Etil acetat je također bitan jer se omjer koncentracije ukupnih estera i koncentracije etil acetata koristi kao indikator kvalitete destilata (Spaho, 2017). Viša vrijednost ovog omjera znači viša kvaliteta konačnog proizvoda.

Etil laktat daje destilatu maslačni karakter te je njegova pojava vezana uz malolaktičnu fermentaciju. U koncentracijama nižim od $154 \mathrm{mg} \mathrm{L-1}$ je poželjan, stabilizira miris i omekšava čvrst karakter određenih spojeva (Soufleros i sur., 2004.). Etil laktat se pronalazi u višim koncentracijama u destilatima dobivenim na „alambic“ uređaju dvostrukom destilacijom (Spaho, 2017). Rast mliječnih bakterija tijekom stacionarne faze na rezidualnim dekstrinima i pentozama koje kvasac ne može fermentirati, trehalozi te dušičnim spojevima produktima autolize kvasaca, smatra se vrijednim izvorom hlapivih spojeva u fermentiranoj sladovini i konačno u samom whisky-u (Barbour i Priest, 1988).

Dietil sukcinat daje patočni i kamforni karakter (Ferreira i sur., 1999) te proizlazi primarno od bakterijskog kvarenja (Karagiannis i Lanaridis, 2002.).

Etilni esteri masnih kiselina srednje dugih lanaca (C6-C12) su od posebnog interesa u fermentiranim pićima zato što pridonose voćnim i cvjetnim aromama, a relativno su visokih koncentracija (Rodriguez i sur., 2013). Etil heksanoat daje voćne arome, pa je poželjan u što većim količinama. Za razliku od njega, etil oktanoat i etil dekanoat su manje intenzivni te daju masne note mirisa (Spaho, 2017).

Kvasac B je proizveo nešto više ukupnih estera izraženih kao etil acetat (Tablica 1 ), dok je gledajući pojedinačne estere (Grafikon 1 ) kvasac A pokazao nešto intenzivniju sintezu etil heksanoata, etil laktata i dietil sukcinata. Takvi rezultati upućuju da je uzorak B bio bogatiji etil acetatom, dok je uzorak A bogatiji ostalim esterima koji pridonose kompleksnosti arome i punoći destilata. To je posebno istaknuto u koncentracijama etil laktata. lako u povišenim koncentracijama vezan uz kvarenje, etil laktat u nižim koncentracijama ima veoma povoljan utjecaj na aromu whiskyja te se navodi kako malolaktična fermentacija krajem alkoholne fermentacije pridonosi u velikoj mjeri rasponu hlapivih spojeva te tako i kvaliteti samog whiskyja (Geddes, 1985, Barbour i Priest, 1988). 


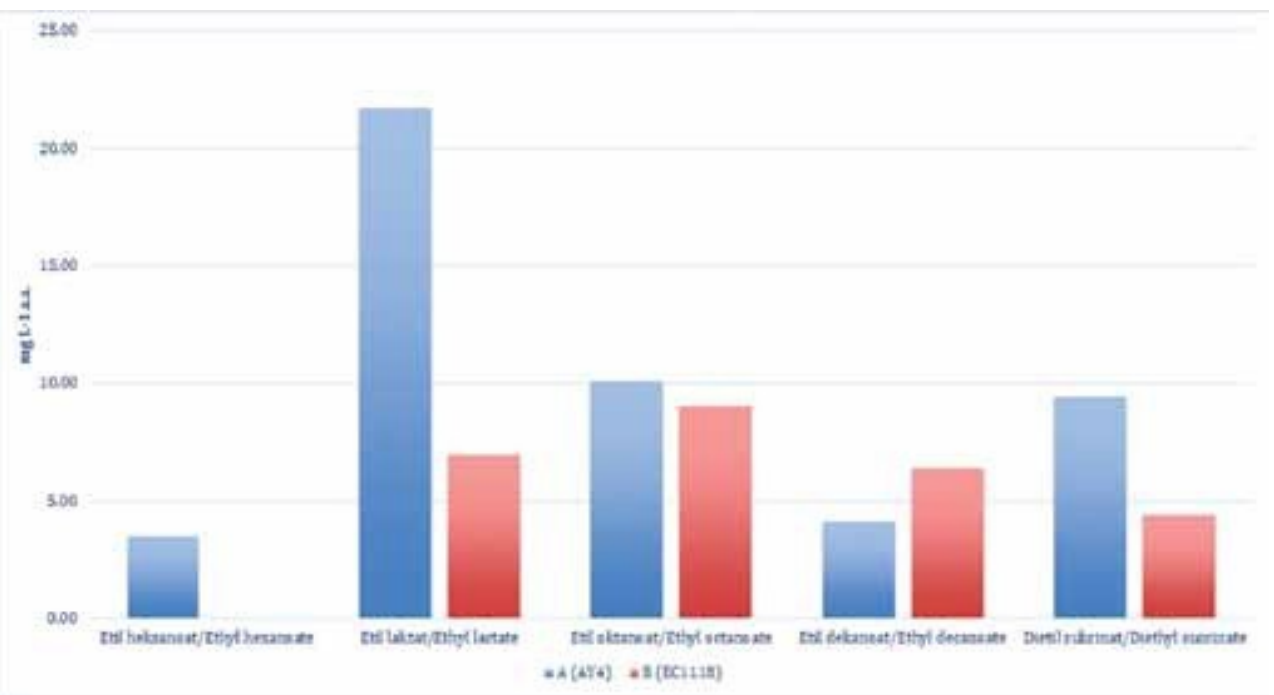

Grafikon 1. Koncentracije estera u uzorcima destilata A (AY4) i B (EC1118)

Graph 1. Ester concentrations in distillate samples A (AY4) i B (EC1118).

\section{Zaključak}

Analizom uzoraka žitnih destilata utvrđena je razlika u radu kvasaca korištenih u pokusu. Vinski kvasac EC1118 Saccharomyces cerevisiae (ex. bayanus) pokazao je sposobnost fermentirati u uvjetima žitne sladovine, te je krajnji proizvod imao dobru alkoholnu jakost. Oba uzorka sadržavali su povišene razine viših alkohola koje odgovaraju razinama pronađenim u whiskyima, ali kvasac EC1118 istaknuo se mnogo višim koncentracijama viših alkohola čije vrijednosti već ulaze u rang destilata slabije kvalitete. S druge strane kvasac AY4 Saccharomyces cerevisiae proizveo je više estera koji pridonose kompleksnosti arome i punoći okusa destilata. Oba kvasca su pokazala kako se mogu koristiti u proizvodnji žitnih destilata te bi daljnjim istraživanjima trebalo ispitati ove kvasce u uvjetima fermentacije kakvi se nalaze u destilerijama.

\section{Napomena/Zahvala}

Rezultati prezentirani u radu nastali su kao rezultat suradnje s mini pivovarom „Angeluš“ u Svetom Ivanu Zelini na čemu smo izuzetno zahvalni!

\section{Literatura}

Barbour, E. A., Priest, F. G. (1988). Some effects of Lactobacillus contamination in scotch whisky fermentations. Journal of the Institute of Brewing, 94(2), 89-92.

Boulton, C. A., Quain, D. E. (2001). Brewing Yeast \& Fermentation. UK: Blackwell.

Campbell I. (2003). Yeast and fermentation. U: Russel I., ur. Whisky Technology, Production and Marketing. 117155. London: Elsevier.

Christoph, N., Bauer-Christoph, C. (2007). Flavour of spirit drinks: raw materials, fermentation, distillation, and ageing. In Flavours and Fragrances (pp. 219-239). Berlin, Heidelberg: Springer.

Cortes S., Gil M. L., Fernandez E. (2005). Volatile composition of traditional and industrial Orujo spirits. Food Control. 16: 383-388. DOI: 10.1016/j.foodcont.2004.04.003.

Cortes S., Rodriguez R., Salgado J.M., Dominguez J.M. (2011). Comparative study between Italian and Spanish grape marc spirits in terms of volatile compounds. Food Control. 22: 673-680. DOI: https://doi.org/10.1016/j.foodcont.2010.09.006

Dolan, T. C. S. (1976). Some aspects of the impact of brewing science on Scotch malt whisky production. Journal of the Institute of Brewing, 82(3), 177-181.

Dolan, T. C. S. (2003). Malt whiskies: raw materials and processing. U: Russel I., ur. Whisky Technology, Production 
and Marketing. 27-68. London: Elsevier

Enari, T. M., Makinen, V., Haikara, A. (1970). The formation of flavour compounds during fermentation. Technical Quarterly. 7(1), 11.

Ferreira V., Hernandez-Orte P., Escudero A., Lopez R., Cacho J. (1999). Semipreperative reversed phase liquid chromatographic fractionation of aroma extracts from wine and other alcoholic beverages. Journal of Chromotography A. 864: 77-88. DOI: 10.1016/S0021-9673(99)01004-3.

Geddes, P. (1985). Bacteriology in the Scotch whisky industry. Journal of the Institute of Brewing, 91, 56-57.

Hammond, J., Brennan, M., Price, A. (1999). The control of microbial spoilage of beer. Journal of the Institute of Brewing, 105(2), 113-120.

Hough, J. S., Briggs, D. E., Stevens, R. i Young, T. W. (1982). Malting and Brewing Science. Volume II, Hopped Wort and Beer. London: Chapman and Hall.

Karagiannis S., Lanaridis P. (2002). Insoluble grape material present in must affects the overall fermentation aroma of dry white wines made from three grape cultivars cultivated in Greece. Journal of Food Science. 67:369-374. DOI: 10.1111/j.1365-2621.2002.tb11412.x.

Kwak H.S., Seo J.S., Hur Y., Shim H.S., Lee Y., Kim M., Jeong Y. (2015). Influence of yeast strains on the physicochemical characteristics, methanol and acetaldehyde profiles and volatile compounds for Korean rice distilled spirit. Journal of the Institute of Brewing. 121: 574-580. DOI: 10.1002/jib.268.

Nykänen, L., Suomalainen, H. (1983). Aroma of beer, wine and distilled alcoholic beverages (Vol. 3). Berlin: Springer Science \& Business Media.

Nykänen L. (1985). Formation and Occurrence of Flavor Compounds in Wine and Distilled Alcoholic Beverages.

American journal of enology and viticulture Vol. 37, No. 1.

Nykänen L., Nykanen I. (1977a). Production of esters by different yeast strains in sugar fermentations. Journal of the Institute of Brewing. 83:30-1.

Nykänen L., Nykanen I., Suomalainen H. (1977b). Distribution of esters produced during sugar fermentation between the yeast cell and the medium. Journal of the Institute of Brewing. 83:32-4.

Pravilnik o analitičkim metodama za jaka alkoholna pića. (2005). Narodne novine br. 138/05.

Rodriguez Madrera R., Garcia Hevia A., Valles B. S. (2013). Comparative study of two aging systems for cider brandy making. Changes in chemical composition. LWT - Food Science and Technology. 54:513-520. DOI: http://dx.doi. org/10.1016/j.lwt.2013.05.037.

Silva M. L., Macedo A. C., Malcata F. X. (2000). Steam distilled spirits from fermented grape pomace. Food Science and Technology International. 6: 285-300. DOI: 10.1177/ 108201320000600403.

Slaughter, J. C. (2003). Biochemistry and physiology of yeast growth. U: Brewing microbiology (pp. 19-66). Boston: Springer.

Soufleros E. H., Mygdalia A. S., Natskouli P. (2004). Characterization and safety evaluation of the traditional Greek fruit distilate „Mouro“ by flavour compounds and mineral analysis. Food Chemistry. 86: 625-636. DOI: 10.1016/j.foodchem.2003.11.006.

Spaho, N. (2017). Distillation techniques in the fruit spirits production. Distillation-Innovative Applications and Modeling. InTech. 129-152.

Sponholz W. R. i Dittrich H.H. (1974). Die Bildung von SO2-bindenden Garungs-Nebenprodukten, hoheren Alkoho-

len und Estern bei einigen fur die Weinbereitung wichtigen,,wilden“ Hefen. Wein Wiss. 29:301-14.

Young, T. W. (1996). Brewing Microbiology, 2. izdanje, London: Chapman and Hall.

https://www.lallemandbrewing.com/en/continental-europe/product-details/lalvin-ec-1118/(Pristupljeno 20.9.2019.)

https://www.aeb-group.com/en/food-beverage/fermoale-ay4 (Pristupljeno 20.9.2019.)

Prispjelo/Received: 4.3.2020.

Prihvaćeno/Accepted: 25.3.2020.

Original scientific paper

\section{Effect of yeast on cereal spirit quality}

\section{Abstract}

The choice of yeast in cereal spirit production can greatly affect ethanol yield, as well as final product quality. The aim of this study was to evaluate the effect of two different yeast on the quality of spirit produced by double distilling a fermented cereal wash on a simple still. Two yeasts were used, Saccharomyces cerevisiae FERMOALE AY4, and Saccharomyces cerevisiae (ex. bayanus) EC1118. Chemical analysis proved that yeast AY4, as expected, has a better ethanol yield (3\% more ethanol), lower titratable acidity, while ethyl acetate concentrationswereslightlyhigherinsample EC1118. Bygaschromatographyanalysishigheracetaldehyde concentrations than usual was identified in samples, in sample AY4 $274 \mathrm{mg}$ L-1 a.a., and $356 \mathrm{mg}$ L-1 a.a. in sample EC1118 was determinated. Furthermore, larger amounts of higher alcohols were produced in both samples, sample AY4 contained 2179 mg L-1 a.a. while sample EC1118 with 3602 mg L-1 a.a. total higher alcohols enter the lesser quality spirit rank. While sample EC1118 was richer with ethyl acetate, sample AY4 had higher concentrations of other esters which made sample AY4 a distillate with more complex aroma and fuller flavour. Future experiments could yield interesting results if the fermentation conditions would match those in a distillery.

Keywords: cereal spirit, yeast, flavour congeners, esters, higher alcohols 